\title{
Report of Outbreak of Ruminal Impaction Due to Indigestible Foreign Bodies in Sheep, in Northwest of Iran
}

\author{
Mohammad Reza Mohebbi* \\ Department of Internal Medicine, University of Tehran, Faculty of Veterinary Medicine, Iran
}

Received: 眥 September 21, 2018; Published: 㘹 September 28, 2018

*Corresponding author: Mohammad Reza Mohebbi, Department of Internal Medicine, Faculty of Veterinary Medicine, University of Tehran, Qareeb Street, Azadi Avenue, Postal Code:1419963111, P.O.Box: 14155-6453, Tehran - Iran

\begin{abstract}
Background: Small ruminants are known to play a very important role in food security in developing countries such as Iran.

Objective: The objective of the study was to identify types and estimate the prevalence of foreign bodies in the rumen and reticulum of involved sheep in the area, and also to evaluate the surgical approach prognosis.

Results: Epidemic occurred in northwestern of Iran. After referring two cases with ruminal impaction to Tehran Veterinary Hospital, a precise clinical examination, epidemiology study, and a herd survey were done. Ultimately, surgery was selected to correct the problem. The incidence and mortality of the disorder were recorded $6 / 25 \%$ and $3.3 \%$ respectively. The prognosis of surgical approach was estimated $90 \%$. On clinical examination of the ram revealed dullness, dehydration, scanty faeces and slight distension of the abdomen at paralumbar fossa. The number of respiration increased, and breathing was accompanied by groan and difficulty in breathing. The foreign bodies were about 2 kilogram in weight and was comprised of rope and plastic in mixed with feces.

Conclusion: It was concluded that large economic losses occur due to ingestion of foreign bodies in sheep. It's conducted that ruminal impaction can result of grazing sheep in polluted pastures with plastics or ropes or other indigestible material or in poor pastures that result in ingestion even the rare foreign bodies. In addition, it was concluded that surgical approach can be helpful in these cases with acceptable prognosis.
\end{abstract}

Keywords: Sheep Rumen Impaction; Surgical Approach; Foreign Body; Iran

\section{Introduction}

Small ruminants (sheep and goats) are known to play a very important role in food security in developing countries such as Iran. This is associated with their small litter size as it favours low investment, small risk of loss and their reproductive efficiency Omoike [1] Bwala [2]. Of world's 1.6 billion sheep and 475 million goats, $65 \%$ and $75 \%$ respectively are located in developing countries Tesfaye [3]. The presence of foreign materials in the rumen and reticulum hampers the absorption of volatile fatty acids and consequently, reduces the rate of animal fattening Igbokwe [4], Roman and Hiwot, [5], Tesfaye [3]. The prevalence of foreign bodies in sheep in different studies were as 9, 29, and 30 in abattoir investigations Tesfaye [3]; Teshome [6], Nigussu Fasil [7]. The most foreign bodies identified were plastic bags, then rope and cloth Abebe \& Nuru [8], Roman \& Hiwot [5]; Sheferaw [9]; Tesfaye [3]. Surgical operation as experimental studies or in case studies (in both small and large ruminant), was successfully done in ruminal impaction Ghurashi [10], Also, 2017; Suthar [11]. In Iran, small ruminants are left to roam and seek their own feed as the raising system is mainly extensive type. The areas available for grazing, particularly in the case for animals reared in the urban and sub-urban areas are polluted with plastics, ropes, hair, wool and metals. In this condition, sheep and goats are very likely to be exposed to various infectious diseases and the ingestion of indigestible materials of various sources. The aim of this report was to investigate the incidence and mortality of this outbreak and was to evaluate the prognosis of surgical operation. 


\section{Materials and Methods}

\section{Area Description}

Disease occurred in northwestern of Iran. The area is semi-arid with Semi-tropical climate, leads to a shortage of food and poor vegetation in the warm seasons.

\section{History of Cases}

Two pregnant ewes, were referred to the Tehran university hospital with signs of Bruxism and inappetence.

The accurate examination was done and the history was taken from the farmer. The flock consisted of 300 sheep. Apart from these two cases, some other cases were involved in the flock, and a number of livestocks were also dead.

\section{Laboratory Tests}

Complete blood count (CBC) and radiograph from abdominal were taken.

\section{Results}

\section{Clinical signs}

Ewes showed dullness, dehydration, scanty faeces and slight distension of the abdomen at paralumbar fossa. 48 cases were involved with the clinical disease (6/25\%). Of these, 10 have been slaughtered; in autopsy, the presence of foreign bodies was confirmed. The mortality rate was $3.3 \%$ and case fatality was $20.8 \%$. Both ewes had a rectal temperature of about 39.4 . The heart rate was recorded at 150 and 102 beats per minute. The respiratory rate was 35 and 40 breaths per minute. The number of respiration increased, and breathing was accompanied by groaning and difficulty in breathing. Within 2 minutes, no sound was heard in the paralumbar fossa. The rumen was touched out of the rigid and massive body. Mouth was frothy. The mucus was pale in both sheep, and in sheep number 2 , the lymphatic nodes slightly enlarged.

\section{Complete Blood Count (CBC) Results:}

Sheep numb 2 showed leukocytosis with neutrophilia, high fibrinogen and Plasma protein rate that indicate the inflammation and probably bacterial infection and or Peritoneum infection (Table 1). Sheep numb 1 showed regenerative anemia with thrombocytopenia, seemingly normal leucon (Table 1).

\section{Radiology Result}

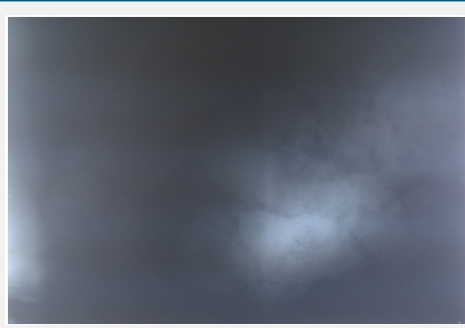

Figure 1: Radio-opaque density in ruminal topographic area.
Radiograph was taken from abdominal cavity in lateral position. In radiograph, a radio-opaque density was revealed at the ruminal topographic area (Figure1).

\section{Surgical Therapy:}

After confirmation of diagnosis in radiology, surgical operation was done in both cases. Paralumbar fossa was chosen as an approach, using paravertebral nerve block was (Figure 2). In rumen the huge foreign body was detected and extracted. It was about 2 kilograms in weight and was comprised of foreign bodies like rope and plastic in mixed with feces (Figure 3). The rumen contents were extracted totally, and then the rumen, abdominal muscles and skin were sutured. 8 more severe cases were referred to the Tehran university hospital for surgical operation. Totally ten severe cases were surgically treated. Nine cases were recovered after a week and started to increase food intake and appetite increased. One case involved with secondary infection and died after three days. So the prognosis of surgical approach was estimated $90 \%$ (Table 1).

Table 1: CBC result in two pregnant.

\begin{tabular}{|c|c|c|}
\hline Index & Sheep Numb 1 & Sheep Numb 2 \\
\hline PCV & 18.3 & 31.1 \\
\hline HB & 5.8 & 10.4 \\
\hline RBC & 6.13 & 10 \\
\hline MCV & 30 & 31 \\
\hline MCH & 9.5 & 10.3 \\
\hline MCHC & 31.9 & 33.3 \\
\hline Plasma protein g/dl & 7.1 & 8.7 \\
\hline Fibrinogen g/dl & .2 & .6 \\
\hline platelets & 61 & 360 \\
\hline WBC & 5.3 & 23.2 \\
\hline Neut. Band \% & 1 & 34 \\
\hline Neut. Seg \% & 60 & 13 \\
\hline Lymphocyte \% & 35 & - \\
\hline Monocyte \% & 2 & - \\
\hline Eosinophil \% & 2 & \\
\hline & & \\
\hline
\end{tabular}

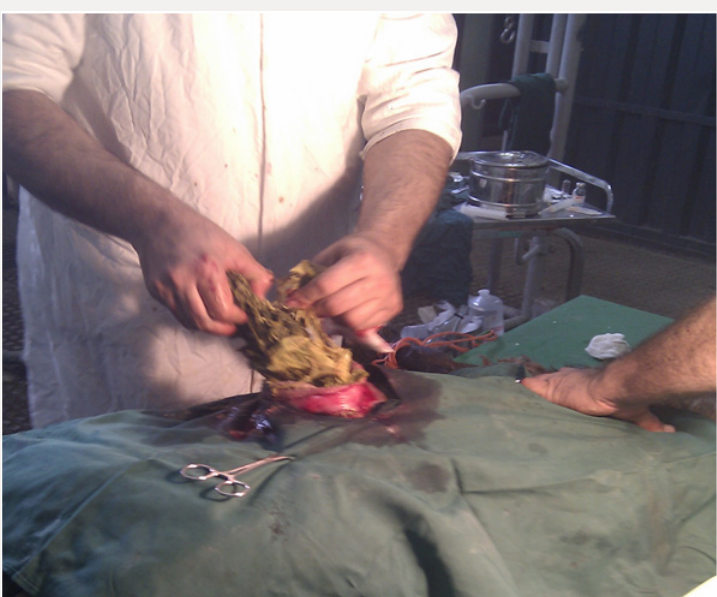

Figure 2: Surgical operation (rumenotomy) and extraction of rumen content. 


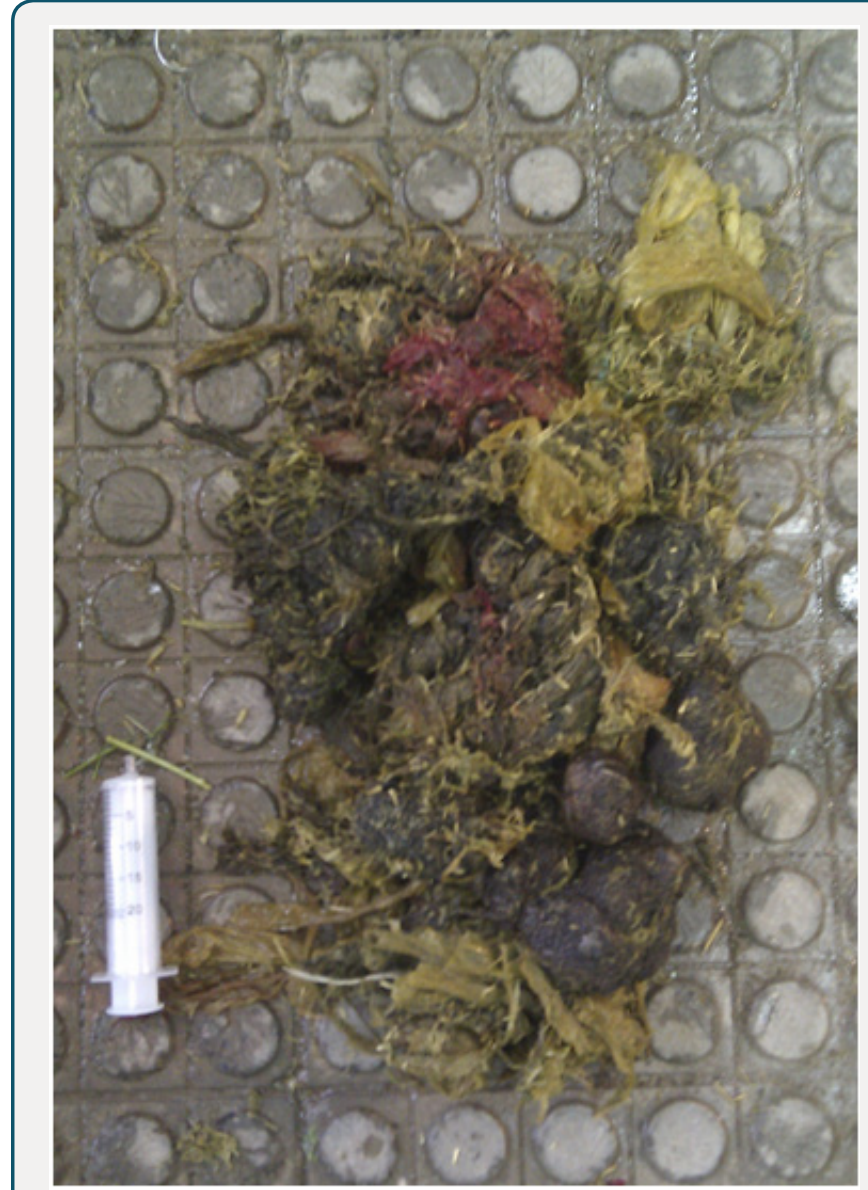

Figure 3: Foreign body extracted from rumen, with tow kilogram weight and consist of plastic and rope in mix with feces.

\section{Discussion}

In the semiarid region of central Iran, the dry season is from May to August. Pasture and supplementary concentrate feed for intensive livestock management are limited and expensive. As a result, most livestock farmers adopt a free-range management system in the urban and semi-urban communities where their animals, mostly sheep and goats, scavenge for food, often going into dumps, which are around the towns.

However, the ingestion of indigestible materials may occur during the period of food scarcity Igbokwe[4], Roman and Hiwot [5] Reports from cattle and sheep reared within urban and suburban environments indicated that impaction of the rumen resulted from the accumulation of foreign bodies, such as plastic bags which cause interference with flow of ingesta leading to the distension of rumen and absence of defection Roman and Hiwot [5]

The fact that rumen impaction by these foreign bodies is mostly asymptomatic in nature and only diagnosed in live animals if the material is accumulated in large amount and thus, in contrary with this study, most studies were done in abattoirs. This was indicated that in this outbreak, both food scarcity and environmental pollution were happen simultaneously, and due to clinical disease. In Hashemiasl study [12] the radiographic approach was used to diagnose the abomasal phytobezoariasis in sheep. Results of this investigation showed that radiography of the abdominal area, 92 $\%$ can diagnose the disorder Hashemiasl [12]. Further more in our study, radiology was used to confirmation diagnosis. In Tesfaye and et al study, from each 288 sheep and goats examined, 28(9.7\%) and $25(8.7 \%)$ were positive for various types of foreign bodies, respectively Tesfaye [3]. In the same survey, A total of 384 sheep and goats were selected using systematic random sampling method and 118 of them (30.73\%) were found positive for foreign bodies in their rumen and/or reticulum Nigussu Fasil [7]. In Teshome and et al investigation the prevalence of foreign bodies in Abattoir, was significantly higher in sheep (29.6\%) and goat (16.7\%) than cattle (14\%) Teshome [6]. In this study, the outbreak of disease was happened and $6.25 \%$ had the clinical signs, but obviously the present of foreign bodies, with no clinical symptom, was significantly more.

In Ghurashi et al experimental study, it is concluded that, surgical removal of the foreign body did improve the health of the animals under investigation Ghurashi [10], also weight gaining was increased during the following weeks. This is consistent with the results of this paper. In our study, gradually after a week, food intake and weight gaining were increased and the prognosis of surgical approach was determined 90\%. Also in Asrat case study in 2017, the cattle with ruminal impaction due to indigestible foreign bodies, around $10 \mathrm{~kg}$ of foreign materials were removed and the animal regained normalcy successfully (Also, 2017). In suthar et al study in 2011, 8 cattle with ruminal impaction were operated and impacted masses were taken out from the rumen, 5 cases out of 8 were recovered (62\%) and others died after few days Suthar [11].

In this study, a large part of the foreign body was in the rumen and small pieces of the reticulum were removed. This finding was in general agreement with the findings of Abebe and Nuru [8], Roman and Hiwot [5] and Tesfaye [3] and may be attributed to the larger rumen volume, the cumulative size/s and material composition of the foreign bodies, and the types of materials, with metals and sharp objects tending to localize preferentially in reticulum Radostits [13], Negash [14]. In Abdullahi and et al study, the haematological parameters of sheep with rumen impaction were within the normal range Abdullahi [15]. In this paper also no pathognomonic changes were found. Pica as one reason of ruminal impaction, may sometimes not be associated with phosphorus deficiency, but rather related to poor nutrition, anemia, iron and cobalt deficiencies and other unknown causes Fraser and Broom [16]; Igbokwe [4]. We also recorded anemia in one case with unknown reason, but because of the outbreak of disease, it can be concluded that the main reason of ruminal impaction in this study is poor and contaminated pasture. 


\section{Conclusion}

It was concluded that a large economic loss can occur due to ingestion of foreign bodies in sheep. Author believe that the success of surgical operation, depends on both the surgeon's skill and the general condition of the patient. And also it was concluded that surgical approach can be helpful in these cases with acceptable prognosis. This condition can be controlled with additional feeding with High quality foods, and Avoidance of grazing on poor and contaminated pastures.

\section{References}

1. Omoike A (2006) Prevalence of Disease among Sheep and Goats in Edo State: Nigeria, Journal Agriculture and Social Research 6(2): 23-31.

2. Bwala DA, Peter ID, Eze CA, Bukar Kolo YM, Bukar MM, et al. (2016) A Study on Rumen Foreign Body Impaction in Sheep Slaughtered the Maiduguri Metropolitan Abattoir: Maiduguri, Nigeria. International Journal of Livestock Research 6(3): 16-23.

3. Tesfaye D, Yismaw S, Demissie, T (2012) Rumenal and Reticular Foreign Bodies in Small Ruminants Slaughtered at Jimma Municipal Abattoir Southwestern Ethiopia: J Vet Adv 2(8): 434-443.

4. Igbokwe IO, Kolo MY, and Egwu GO (2003) Rumen impaction in sheep with indigestible foreign bodies in the semi-arid region of Nigeria: Small Ruminant Research 49: 141-146.

5. Roman T, Hiwot Y (2010) Occurrence of rumen foreign bodies in sheep and goats slaughtered at the Addis Ababa Municipality Abattoir: Ethiop Vet J 14(1): 91-100.

6. Teshome E, Abdela N, and Hassan A (2017) Postmortem Study on Indigestible Foreign Bodies in Rumen and Reticulum of Ruminants Slaughtered at Asella Municipal Abattoir, Southeastern Ethiopia: J Vet Sci Technol 8:3.
7. Nigussu Fasil L (2016) Assessment of Sheep and Goat Foreign Bodies in Rumen and Reticulum in the Jigjiga Municipal Abattiar J Adv Dairy Res 4: 3.

8. Abebe F, Nuru M (2011) Prevalence of indigestible foreign body ingestion in small ruminants slaughtered at Luna export abattoir: East Shoa, Ethiopia, Journal of Animal and Veterinary Advances 10(12): 1598-1602.

9. Sheferaw D, Fikreysus, G Metenyelesh A, Tesfaye D, Etana, et al. (2014) Ingestion of indigestible foreign materials by free grazing ruminants in Amhara Region, Ethiopia: Tropical Animal Health and Production 46: 247-250.

10. Ghurashi MAH, Seri HI, Bakheit AH, Ashwag EAM (2009) Effect of Surgical Removal of Foreign Body from Goat's Rumen with Special Reference to the Prevalence of Foreign Body in Goats in Southern Darfur: Australian Journal of Basic and Applied Sciences 3(2): 664-668.

11. Suthar D, Jhala SK, Bhatt RH, Patel JB, joy N et al. (2011) Surgical management of ruminal impaction due to non-penetrating foreign body syndrome in Kankrej cattle: IJAVMS 5(5): 477-480.

12. Hashemiasl SM, Azizi S, Torkamani D (2016) Radiographic findings in sheep with abomasal phytobezoariasis: Veterinarni Medicina 61(8): 436-442.

13. Radostits OM, Gay CC, Hinchcliff KW, Constable PD (2007) Veterinary medicine: A textbook of the diseases of cattle, horses, sheep, pigs and goats. $\left(10^{\text {th }}\right.$ edn.). Saunders, Elsevier,London.

14. Negash S, Sibhat B, Sheferaw D (2015) A postmortem study on indigestible foreign bodies in the rumen and reticulum of ruminants: eastern Ethiopia.Onderstepoort J Vet Res 82.

15. Asrat M (2017) Surgical management of ruminal impaction due to indigestible foreign bodies in cattle, VET 2(1): 26-27.

16. Fraser AF, Broom DM (1990) Farm Animal Behaviour and Welfare: (3 ${ }^{\text {rd }}$ edn.). ELBS Bailliere Tindall, London pp. 318-322.
This work is licensed under Creative Commons Attribution 4.0 License

Submission Link:

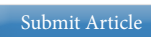

DOI: $10.32474 / C D V S .2018 .02 .000127$.

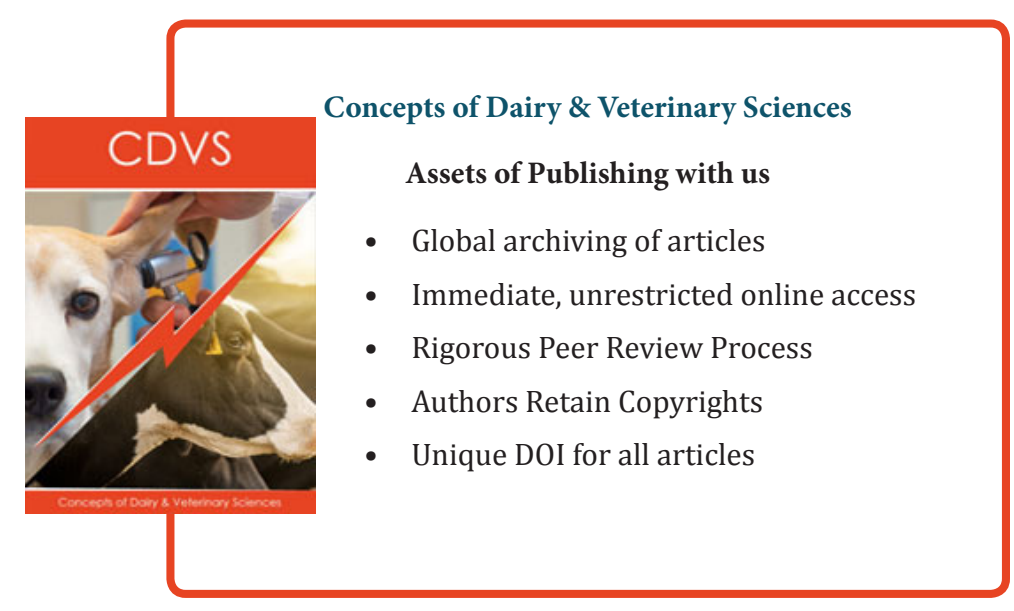

